\title{
Roger Bastide e a experiência compartilhada
}

\author{
MARIa de Lourdes PATRINI \\ Universidade Federal do Rio Grande do Norte
}

RESUMO: NA OBRA AUTOGRÁFICA DE ROGER BASTIDE HÁ UMA FORTE PRESENÇA DE COLABORADORES, COMO SE HOUVESSE UMA SOCIABILLDADE DE CRIAÇÃO. EM SEUS REGISTROS, PRODUZIDOS NA CONVIVÊNCIA DO DISCURSO ANTROPOLÓGICO E DO DIÁRIO PESSOAL, ENTREMEIAM-SE VOZES DE PESQUISADORES, SUJEITOS PARTICIPANTES DA PESQUISA DO ANTROPÓLOGO. ÀS ESCONDIDAS OU ATRAVÉS DE JOGOS MAIS OU MENOS DISSIMULADOS REALIZADOS PELA INTERFERÊNCIA E PELA INTERLOCUÇÃO, DESVENDA-SE A PRESENCCA CÚMPLICE E MARCANTE, DE CARÁTER REFLEXIVO E CIENTÍFCO 'DE PIERRE VERGER' NA ESCRITURA DE CAMPO DE ROGER BASTIDE.

RESUMEN: EN LA OBRA AUTOBIOGRÁFICA DE ROGER BASTIDE HAY FUERTE PRESENCIA DE LOS COLABORADORES, COMO SI HUBIERA UNA SOCIABILIDAD DE CREACIÓN. EN SUS REGISTROS, PRODUCIDOS EN LA CONVIVENCIA DEL DISCURSO ANTROPOLÓGICO Y DEL DIARIO PERSONAL, SE MEZCLAN VOCES DE INVESTIGADORES, SUJETOS PARTICIPANTES DE LA INVESTIGACIÓN DEL ANTROLPÓLOGO. A ESCONDIDAS O A TRAVÉS DE JUEGOS MÁS O MENOS DISIMULADOS REALIZADOS POR LA INTERFERENCIA Y POR LA INTERLOCUCIÓN, SE REVELA LA PRESENCIA CÓMPLICE Y MARCANTE, DE CARÁCTER REFLEXIVO Y CIENTÍFICO 'DE PIERRE VERGER' EN LA ESCRITURA DE CAMPO DE ROGER BASTIDE.

PALAVRAS-CHAVE: MANUSCRITO, CADERNO DE CAMPO, ROGER BASTIDE, PIERRE VERGER, ESCRITURA.

PALABRAS-CLAVE: MANUSCRITO, CUADERNO DE CAMPO, ROGER BASTIDE, PIERRE VERGER, ESCRITURA. 
diário é um texto polifônico. É um documento crucial para a história da antropologia, não porque revela a realidade da experiência etnográfica, mas porque nos força a enfrentar as complexidades de tais encontros e a tratar os relatos textuais baseados em trabalho de campo como construções parciais.

James Clifford

A escritura epistolar tem muitos aspectos. A carta distanciada de seus atores torna-se documento; é uma prática de escritura, um objeto que se troca, um texto autográfico, um ato de escritura onde estão em cena: eu, ele e os outros. Por isso, escrever, ler e reler cartas é sempre uma aventura. E essa aventura esteve sempre presente na vida de Roger Bastide.

A correspondência foi entre outros meios uma prática de escritura que tornou possível a troca de experiência efetivando um saber compartilhado. Bastide manteve correspondência constante com intelectuais, escritores, poetas e políticos brasileiros e estrangeiros. Alguns deles durante anos e até décadas e outros por toda a vida. A carta por definição é algo que se compartilha, e Bastide soube como fazer uso dessa prerrogativa em sua vida pessoal de estudioso e pesquisador.

Se a correspondência foi para ele um meio de contato, de aprofundamento de amizades, de troca de idéias e de debates sem fim e uma prática que marcou o seu percurso de pesquisador e a sua obra, a escritura de campo será o terreno propício para que essa interlocução observada na escritura epistolar se efetive. Vozes estarão atuando nos interstícios da escritura do antropólogo, muitas vezes não tão expostas como as que encontramos nas cartas. Por outro lado, na escritura de campo, elas ganham em poder e diálogo. Às vezes de forma sutil essas vozes dividem com a dupla, antropólogo e objeto de estudo, o espaço e o momento histórico da interpretação. Assim, num apelo solene, essas vozes são chamadas a intervir na dinâmica dos fatos narrados, chegando a se corporificarem enquanto presenças gráficas e, em outros momentos, a contribuir em narrativa dos fatos que estão sendo narrados e registrados assim como na interpretação dessa narrativa, outorgando voz aos conteúdos ali explicitados.

A leitura de inúmeras cartas recebidas por Bastide apontou-me caminhos para que pudesse compreender certas escolhas, acompanhar itinerários, conhecer mais profundamente as intenções que determinaram as buscas do 
estudioso, seus conflitos e, por que não dizer, alguns mistérios que envolvem este "savoir-faire". Muitas dessas cartas me revelaram os contornos de amizades e perfis do homem e do pesquisador. Tecendo os fios fornecidos por uma rede de informações diversas, adicionados àqueles provenientes da escritura epistolar, compreendi a dimensão da amizade de Roger Bastide e Pierre Verger e, mais que isso, a importância que ambos tiveram na construção das respectivas obras.

\section{A chave dos mistérios}

As cartas foram imprescindíveis e fundamentais para minha compreensão de certas passagens da escritura de campo. Apontaram-me caminhos elucidando fatos e propósitos, desvendaram presenças, vozes e grafias. Graças à leitura das cartas, pude reconhecer a presença de uma outra escrita/ grafia corporificada na escritura de campo e identificar o seu autor. Por meio de um jogo de combinações confirmei datas. As cartas me contaram a história de uma amizade e de uma cumplicidade profissional fundamentada na lealdade e no respeito. Mas elas também me contaram outra história: como tornar possível um desejo de uma busca profissional acalentado por muito tempo, como realizar um sonho de viagem à África, como compartilhar a concretização dessa experiência. Estas histórias estavam recontadas no diário de campo pelos mesmos sujeitos; elas faziam parte da criação e da produção científica do antropólogo. Sem as cartas, muito teria se perdido.

Desta forma, na multiplicidade de vozes, nos interstícios desse contar, Bastide abre o diálogo e o espaço para uma presença corporificada na malha de sua narrativa de campo.

Se nesse momento, a escritura epistolar cede lugar à escritura de campo, passando a figurar como pano de fundo, ela continuará sempre a fazer parte da rotina do pesquisador onde quer que ele esteja.

Vendredi 22 août Lettre $n^{\circ} 18^{1}$

Ce matin, je suis allé chez les Chacha (De Souza)

${ }^{1}$ Os textos citados do diário de campo e de outros manuscritos de Roger Bastide estarão sempre em itálico. 
Ensuite, je vais travailler à la Mairie.

Notes de lecture

Samedi 30 août - Lettre 23

Depense de voyage : $17000 \mathrm{fr}$

(...) Départ de Abomey vers 8:30 - arrivée à Cotonou um peu avant 11 heures. Passer banque, puis prendre d'argent. Arrivée à Porto Novo à $12 \mathrm{~h}$. Je suis allé déjeuner au restaurant

Après toilette, correspondance, lecture et dîner au restaurant.

Notes de lecture

Esses pequenos trechos do diário ilustram o que foi dito acima. Logo ao lado da data há o numero da carta que Bastide escreveu. No outro fragmento, ele registrou no texto tarefas a cumprir e entre elas está a correspondência.

A escritura epistolar gera o confronto entre estudiosos e entre seus objetos de pesquisa, estimulando o enriquecimento da troca de idéias. Foram as cartas, as trocas de intenções, de desejos e vozes vindas de longe que levaram Roger Bastide à África, em 1958, em busca do seu objeto de estudo. Ele chegou a Cotonou no dia 13 de julho e foi recebido no aeroporto por seu amigo e antropólogo Pierre Verger.

\section{A escritura do caderno de campo}

A prática de escritura de campo, por sua vez, vai colocar pesquisador e ou pesquisadores e pesquisado face a face. E, nesse caso, a primeira pessoa é um "eu" narrador, autor e ator que conta os acontecimentos e faz de sua experiência o centro de atenção da narração relatada por ele mesmo. Esse "eu" ou "nós" vai às vezes ocupar na escritura o papel de sujeito, outras vezes de objeto. A escritura do caderno de campo nos mostra como o pesquisador sai de seu papel tradicional de observador profissional e ainda nos revela o entrelaçamento da aventura pessoal interior do antropólogo com a realidade exterior de que ele bravamente procura dar conta.

Considero que a escritura dos cadernos de campo seja uma prática na qual o antropólogo concebe o campo como uma ação - para o registro de suas 
observações, mas que deve, no entanto, ser relacionada à memória e à conservação dos dados extraídos do campo. A escritura de campo deve organizar uma relação: o "eu" e o "outro". O "sujet scripteur" deve distingui-los bem, articulando o tempo da escritura, o tempo dos fatos observados, o tempo de uma história de vida e o tempo social. Essa é a dinâmica adotada por Bastide, presente nos seus "cadernos de campo" através de seus registros, observações, notas e dados. Ele soube ser um viajante e um cartógrafo, ${ }^{2}$ soube onde se situar, aceitando o difícil desafio de, sem perder a visão íntima, fazer a avaliação durante seu trabalho de campo. ${ }^{3}$

Roger Bastide após sua chegada em Cotonou, África do Oeste, registra em seu caderno I - Mon Journal:

13 juillet

Arrivée Kotonou - Verger m'attend avec camionnette IFAN. ${ }^{4}$ Beau temps, mais nuages vers le soir. Départ pour Ouidah ${ }^{5}$ (40 Km environ) un dîner chez M. Bisson, maire. La maison me rappelle étrangement le Brésil : on mange dehors, en se servant soi-même, parmi les fleurs, les arbres, sous un manguier. Paysage un peu récifien, ${ }^{6}$ un peu Apipucos. Plusieurs membres de la « colonie française », blancs ou Martiniquais, Guyanais - Le matin, visite du marché L’après-midi, visite du quartier « Brésil ». Répétition de la « Burrinha».?

Os manuscritos convidam o leitor a participar de uma leitura do texto em formação, a refletir sobre as condições de sua emergência. Os cadernos de campo de Roger Bastide permitem também entrever certas operações de escritura que são determinantes para a produção de seus textos. ${ }^{8}$ Desta concepção autoral da

${ }^{2}$ GEERTZ, Clifford. Ici et là-bas - L'anthropologue comme auteur. Paris : 1996, p.18. Utiliza a expressão "voyageur et cartographe"

${ }^{3}$ Idem, ibidem, p.18.

${ }^{4}$ IFAN : Institut français de l'Afrique noire.

${ }^{5}$ Ouidah $=$ Uidá.

${ }^{6}$ Os dicionários: Larousse (2002) e Le Petit Robert (CD 2001-2003) trazem o substantivo récif e o adjetivo récifal,e, aux. A forma utilizada por Bastide não consta nesses dicionários. A palavra recifien talvez faça parte das conhecidas adaptações (francês e português) criadas e utilizadas por Bastide.

7 "Burrinha" é o nome que recebe em Dahomé a festa popular do "Bumba-meu-boi".

${ }^{8}$ Como já fora mencionado, os textos que poderiam ter sido produzidos a partir do material extraído do 
narratividade, remarcamos uma valorização de um dos elementos que compõem sua escritura: o seu objeto de estudo enquanto realidade cultural, histórica, social e literária. Este elemento, motivo de busca constante, aparece nos cadernos de campo de Bastide não somente como o principal organizador textual, pois nesse espaço de escritura o objeto de pesquisa é também o elemento de inúmeras representações pictóricas que certamente problematizam as relações entre texto e imagem.

Além dessas representações, a escritura de campo sobre sua viagem de estudos à África do Oeste traz, nas malhas de sua organização textual, presenças, vozes e marcas escriturais esclarecedoras e decisivas para a compreensão, revelando a confiança e a disposição generosa do autor para a troca científica. Cede também o lugar para que não somente o diálogo seja enriquecido, mas para que a criação ganhe a participação do "outro".

Se o percurso da viagem é importante, " quero ressaltar neste trabalho a importância de um outro percurso, o da produção de uma narrativa e da produção de conhecimento elaborado por Roger Bastide durante sua viagem de estudo à África, Dahomey e Nigeria, hoje Benin e Nigéria.

\section{Bastide e Verger entre narradores e narratários}

Pretendo não somente assinalar essas diferenças como ver se pego a toada originária ou o que dela restar na África e por isso estou em relação com o Institut d'Afrique Noir.

Roger Bastide

Este texto é parte da carta-resposta a René Ribeiro. Nesta mesma carta menciona as fotos de P.Verger (...) e no final coloca a seguinte mensagem em destaque: PS: Junto a pedido de Verger uma fotografia da qual ele deve ter falado em carta.

\footnotetext{
campo, infelizmente, não foram publicados. Além de alguns artigos que ele rapidamente produziu para publicação em periódicos, muitos dos quais em parceria com Pierre Verger. Em 2002, tivemos a publicação do livro: Verger/Bastide. Dimensões de uma amiz̧ade, organização de Ângela Lühning, com alguns artigos referentes a essa viagem.

${ }^{9}$ Construí o percurso dessa viagem segundo o caderno de campo «Mon Journal». Ele foi enviado, conforme solicitação, à Fundação Pierre Verger.
} 
A interlocução permite o aperfeiçoamento dos conceitos elaborados sobre uma prática na qual estão colocados em relação narradores e narratários, ambos estimulando a produção de narrativas por meio de um percurso de observação, formação e criação. Nesse sentido, ela contribui, também, para a sistematização de princípios de compreensão e interpretação, estimulando o surgimento de novas pesquisas. A participação constante do antropólogo Pierre Verger, presente na escritura de campo e nas peculiaridades deste discurso híbrido, se faz por meio de formas mais ou menos evidentes ou mais ou menos intencionais. Trata-se às vezes de uma participação discreta, objetiva e, neste caso, anunciada por meio de notas, lembretes e ou citações breves, ocupando timidamente as margens do suporte e da escritura, mantida sempre em total convivência com o autor. Outras vezes, a presença dessa voz entra sorrateiramente, mas de forma contundente penetrando a escritura, surpreendendo algumas vezes o "autor" e desafiando o leitor/pesquisador. Dentre todas essas formas de presenças há ainda aquela que, apesar do livre acesso concedido e do pacto estabelecido, escapa do controle e desorienta o leitor/pesquisador, que se vê diante de um texto a quatro mãos. Ao mesmo tempo em que a escritura revela e exibe a olhos nus essa presença, nem sempre a identidade do "outro" está evidente. Os detalhes se acumulam e pistas indicam probabilidades, mas a comprovação desses sinais e traços somente será alcançada com o conhecimento aprofundado da obra manuscrita dos autores. Assim, às escondidas ou por meio de jogos mais ou menos dissimulados, realizados pela interferência e pela interlocução, desvenda-se a presença cúmplice e marcante, de caráter reflexivo e científico de Pierre Verger na escritura de campo de Bastide.

\section{A voz "en cachette"}

Quando Bastide chega à África, em Cotonou, em julho de 1958, ${ }^{10}$ ficamos sabendo pela leitura de seu diário de campo que Pierre Verger também está nesse mesmo lugar:

\footnotetext{
${ }^{10}$ Obtive a confirmação do ano dessa viagem depois de muita busca entre as diversas práticas de escritura contidas no arquivo da obra manuscrita de Roger Bastide.
} 
13 juillet

Arrivée Kotonou - Verger m'attend avec camionnette IFAN.

Primeira linha do diário e já estamos diante de uma surpresa e de algumas questões: Será apenas uma recepção? Será que para os antropólogos esta viagem tem interesses comuns?

14 juillet Nous devons partir pour Ifahin. Mais les évenements vont se succèder si nombreux que difficille de donner description detaillée. $V$. d'ailleurs me racontera cela.

Neste segundo dia de sua estada no campo, surge na escritura a primeira pessoa do plural. Seria somente um disfarce narrativo? Ou Verger segue também em viagem? - Segundo dia de sua estada no campo.

Jeudi 17 juillet Visite chef de cabinet (...) soir, visite de la ville avec $V$.

Quatro ou cinco linhas abaixo temos: L’après midi, visite du quartier "Brésilien", Répetition de la 'Burrinha' (...)

A escritura confirma, embora de forma discreta, a presença de Verger.

Bastide descreve o ensaio da 'Burrinha' (Bumba-meu-boi) e, em meio à sua descrição, dá continuidade ao seu texto, registrando que (...) Verger (...) copie les chants plus nettement brésiliens de Porto Novo (...).

A participação é reservada, mas a escrita deixa claro que ambos estão a compartilhar do mesmo momento, ou seja, juntos presenciam o espetáculo da 'Burrinha'. Mais algumas linhas abaixo e Bastide coloca do lado direito do seu texto a observação entre parênteses: em $52 \mathrm{~V}$. l'a vu sortir (...).

Neste caso, o "outro", mesmo estando de forma circunscrita na escritura, tem uma participação notória na narrativa. Dessa forma, a experiência do "outro" direta ou indiretamente atua na observação e na criação da escritura de Bastide.

Entre questões, problemas, comparações e hipóteses, o discurso vai se construindo narrando e/ou descrevendo, enumerando, resumindo e à noite um novo espetáculo é presenciado; e na escritura do antropólogo uma vez mais ele fará um apelo ao trabalho de Verger: "Voir photos Verger", colocado à margem do texto. Com o objetivo de dar completude e vigor a sua argumentação, Bastide não deixa de recorrer ao "outro" e à sua obra. 
Assim, desde o início, o leitor/pesquisador reconhece uma diversidade de movimentos empreendidos pela própria escritura que se entrecruza. São dinâmicas singulares, mas que corroboram entre si, dando sentido ao todo discursivo que se constrói numa "desconstrução" aparente e constante. Para J. Derrida «La "desconstruction" est un travail de sape de la pensée qui consiste à passer au crible les textes philosophiques ou littéraires pour montrer comment 'les effets de verité' sont le produit de jeux de langage, de jeux d'écriture. » ${ }^{11}$

\section{O artesanato organizado}

A memória do vivido, do observado e do compartilhado se faz palavra que terá como suporte a escrita do antropólogo, que fixada no suporte da página pela escritura adquire, com a leitura, a análise e a interpretação, mobilidade e conseqüente alteração de poder.

E assim, o "outro", tão presente desde a primeira página do diário, vai pouco a pouco sendo visualizado, compreendido. Ao meu ver, isso só acontece "pela ênfase sobre processos de interlocução, nos quais a autoridade dos interlocutores para falar sobre e por si mesmos seja a priori e mutuamente reconhecida" (Versiani, 2005: p.22), mesmo se a presença do "outro", até aqui apresentada, está ainda sob o domínio da solicitação de um "eu" que controla o processo de construção do discurso etnográfico.

A minha atenção, neste artigo, está voltada prioritariamente para a noção de sujeito enquanto singularidade e complexidade do self que se constrói pelo "acúmulo de suas múltiplas pertenças e experiências passadas, decorrentes de sua singular trajetória de identificações com diferentes grupos socioculturais, memórias e tradições”. (Versiani, 2005: p.23). Isso conduz também a uma reflexão sobre suas implicações para a produção de conhecimento quer seja o denominado do "senso comum" ou o formal.

Nesse sentido, meu estudo sobre a presença do "outro" na escritura de campo de Roger Bastide só é viável pela ênfase nos processos de interlocução,

\footnotetext{
${ }^{11}$ Ver DERRIDA, Jacques. «Les logiques de l'écriture». Sciences humaines, Paris: (109): 26, out. 2000.
} 
que substituem a descrição do outro pelo diálogo interminável e tenso entre subjetividades distintas. Desta forma, a escrita é abordada não como reprodução da realidade exterior, mas questionada em favor de seu estatuto performático de evento. (Versiani, 2005: p 13).

O leitor/pesquisador vivendo ainda a emoção da descoberta do diário do antropólogo e no seu empenho em decodificar a escritura segue adiante perguntando se estaria o "outro" também fazendo as suas anotações? Haveria uma outra narrativa da mesma performance? Como estaria o outro materializando em escritura essa experiência?

Mas até aquele momento a presença do outro era discreta. Bastide, dono de sua escritura, concedia comedidamente uma presença indireta ao "outro" em meio as suas notas, em meio a sua voz de sujeito da escritura.

Passado o primeiro impacto causado pelas descobertas, leituras sucessivas são realizadas e, assim, o estudioso da escritura começa a compreender a presença do outro na escritura de campo do antropólogo e perceber que uma mudança de nível acontece na participação do "outro", observada logo na primeira página do diário. Primeiramente, temos um encontro. Assim, o surgimento do "outro" na escritura leva o leitor a reconhecer e confirmar, nesse encontro, uma relação de amizade, uma acolhida fraterna de ambas as partes, oriunda do campo pessoal. Obviamente o leitor ainda não se interou da cumplicidade profissional que envolve esse encontro. Ele pode, no entanto, supor que há uma intenção profissional nesse encontro, mas ele ainda não está configurado na escritura. Enquanto avança na leitura do diário, o leitor/pesquisador percebe que a presença do "outro", ainda pouco delineada, ganha espaço e assume o papel de interlocutor, caracterizando uma situação de participação na criação e produção de conhecimentos do processo científico do antropólogo.

Vale salientar neste momento que não se trata de entender a etnografia apenas como "textos" no sentido estrito do termo. Segundo James Clifford, eles fazem parte de um sistema complexo de relações; são pensados simultaneamente como condições e efeitos de uma rede de relações vividas pelos etnógrafos e outros personagens. A etnografia se configura como um "campo articulado pelas tensões, ambigüidades e indeterminações próprias do sistema de relações do qual faz parte". (Gonçalves, 2002: p.10).

Nas páginas 8 e 9 de seu diário, Bastide faz a descrição da visita feita a Shangô chez, le Roi. Ele tece comparações, tendo como ponto de referência sua 
experiência brasileira. Dando continuidade às suas anotações, sempre com seu estilo econômico, conciso, centrado e objetivo, corporifica os desenhos, as questões e as hipóteses. Em seguida, por meio de um discurso indireto livre, ele abre o diálogo: "D’après Verger Shangô (...). Como um narrador onisciente transmite ao leitor o parecer do "outro" para em seguida complementar:

Vendredi 8 août - terminé la lettre $n^{\circ} 9$

- Fête de Oshum à Oshogbo.

(...) Voir dans le livre V. le mythe qui explique cette fête d’Oshum. (...)

Algumas linhas abaixo, fazendo uso da mesma técnica:

V. qui photographiant me renseignera la dessus.

Puis dîner. Après conversation avec Verger. 1) V. me confirme que le Roi était bien présent sur le rivage au moment de l'offrande de nourriture. 2), 3), 4)... (...)

A partir do diálogo com Pierre Verger, Bastide organiza um breve resumo em quatro itens que passa a fazer parte do seu relato. Em seguida, retoma sua escritura, agora na primeira pessoa do singular:

Je reprends maintenant la description de la cérémonie:

As vozes entre a oralidade e a escrita ziguezagueiam na narrativa em construção.

Na página 23 de seu diário, após ter copiado alguns cantos, como ele mesmo anota: Orthographe brésilienne fantaisiste que je recopie telle quelle; o "outro" está presente apenas como uma referência. Ao lado direito deste registro anota: Cf. Verger - afro brésilien $n^{\circ} 1$; e algumas linhas depois: of. Verger $n^{\circ} 10 .^{12}$

Por meio da escritura pessoal, próxima a dos diários íntimos, Bastide não deixa de confirmar a presença silenciosa, mas constante e imprescindível do amigo:

\footnotetext{
${ }^{12}$ A pesquisa junto à obra manuscrita do antropólogo deu-me condições de saber que esta numeração refere-se às fotos de autoria de Verger, contidas em sua obra.
} 
Après - midi: repos, lecture.

(...) le soir, V. est allé faire 1 tour.

Inúmeras leituras do diário de campo - cabier I, Mon Journal como Bastide o denominou. Algumas páginas foram lidas e relidas sistematicamente. Quando encontrei esse diário, ainda me perguntava em que ano essa viagem à África teria acontecido, pois o antropólogo fez várias viagens a esse continente. Bastide inicia o seu diário marcando apenas 13 juillet. Nas primeiras páginas além da presença de Verger há uma série de dados indecifráveis para o leitor/pesquisador. Além da escritura ali exposta na sua materialidade: letra miúda, com abreviações, economia de meios, poucas rasuras, economia de espaços e diversidade de informações, estavam a conviver práticas de escritura diferentes. No meu ponto de vista, na primeira página do diário está o início de tudo; apesar de em forma cifrada, o objeto esta inscrito juntamente com as questões que o preocupam e as hipóteses que acompanham o pesquisador. As três primeiras páginas abrigam dados importantíssimos sobre o confronto entre o "eu" e o "outro" e entre eles o registro de que há um outro caderno que ele chama de especial com as notas sobre a Cérémonie de Shangô.

Entendo que além do entrelaçamento de vozes narrativas, o apagamento de fronteiras entre os suportes é confirmado pela circulação de comunicados registrados aqui e acolá e anunciados pela voz do próprio antropólogo. Nesse caso, cabe ao estudioso descobrir as conexões dos suportes e dos dados registrados e estabelecer as relações, ser o mediador entre os dados e seus suportes e as diversas vozes que os compõem para analisar a narrativa etnográfica que terá diante de si.

O retorno da segunda pessoa do plural à narrativa, desta vez intercalada pela terceira pessoa impessoal, confirma a mistura de vozes narrativas que são incorporadas ao texto. Os exemplos abaixo ilustram que na narrativa do antropólogo há a presença de uma subjetividade autobiográfica, mas que vai além do estritamente pessoal, pois ela acolhe o "outro" ou os "outros" numa ação interativa. Entretanto, como mostra o fragmento abaixo, essa subjetividade detém as vozes que estruturam a narrativa. Ao mesmo tempo em que outorga liberdade de atuação ao "outro", refreia-a, mantendo-a "en cachette" por um "eu” que não abre mão da sua autoridade no discurso. 


\section{Mardi 29 - lettre $n^{\circ} 2$}

Matin: Kotonou, démarche par le Nigeria. Mais on ne peut nous donner que des rendez-vous pour demain matin. Au retour, chaleur escaldante longue sieste aussi - Donner des ordes à celui qui veut étudier les marchés - Verger l'accompagne au Marché de Porto Novo, pour mieux lui indiquer ce qu'il faut faire, d'après le plan que j'ai tracé. Mais je suis trop fatigué pour l'accompagner (..)

\section{Samedi 2 août - lettre $n^{\circ} 6$}

Dejeuner avec V. L'après-midi, visite de la ville et plus particulièrment du quartier brésilien.

Mercredi 6 août -

Matin : Visite du Roi de Ilobu dans son palais

Départ par Oshogbo - Visite du Roi de Oshogbo.

La Iya Osum nous rend visite avec un masque particulier (voir photo de V.)

Em mardi 12 août, há um misto de escritura de agenda e diário íntimo: notas pessoais próximas de uma escritura privada e notas profissionais se misturam. No final, há também o endereço de um aluno registrado com letra diferente da de Bastide; presença corporificada do "outro" na escritura do diário de campo. Seria a de Pierre Verger?

Em outros momentos, o narrador ao se locomover da escritura íntima para um discurso indireto livre faz o leitor conhecer as reflexões, as questões que preocupam e que são caras ao "outro". Essa atitude demonstraria um processo de construção de uma outra subjetividade no discurso?

\section{Samedi 16 août lettre 13}

Parler après le déjeuner avec V. de Ondo, Are (...)

Aujourd'hui fait un peu de correspondance. Je ne suis pas sorti. V. est un peu fatigué. V. me parle malgré son mal de tête à nouveau de Ondo. Il se demande, étant que donnée que le rituel est le même que celui de Ogun, qu’il a décrit, si Ondo ne serait pas 1 nom de Ogun plutôt que (...).

Roger Bastide, após a prática já constante de troca de experiências por meio da oralidade, retorna à primeira pessoa, escritura pessoal e íntima na qual in- 
clui o "outro". Um diário íntimo a quatro mãos? A amplitude e a importância das reflexões do "outro" são reveladas ao antropólogo, que as registram, por uma prática heterogênea de escritura. A escritura pessoal cede lugar à produção de conhecimento formulada nesse momento por meio de questões.

Desta forma, entre as trocas vindas da oralidade e as absorvidas pelas fontes escritas, o manuscrito da experiência da pesquisa de campo é construído:

Dimanche 17 août - Lettre $n^{\circ} 14$

Je continue pas à prendre des notes sur le livre de Johnson. Il me paraît si important que j'ai demandé à $\mathrm{V}$. de m'en acheter un exemplaire quand il retournera au Nigeria. Je note seulement les pages à revoir à Paris.

Lundi 18 août - lettre $n^{\circ} 15$

Observamos nas anotações do antropólogo comparações importantes que por meio do diálogo tornam presente na escritura a ação colaborativa e interativa na pesquisa de campo do "eu" e do "outro".

Conversation avec V. sur comparaison entre Eguns à Bahia et ici.

Parti trop tard, nous sommes arrivés au baptême quand les Babas étaient partis. Nous avons fait un tour au Marché.

Jeudi 21 août - lettre $n^{\circ} 18$

Aujourd'hui, je suis parti à Ouidah pour étudier les Brésiliens 9h 30

Arrêt à Cotonou.

Départ à 1 heure, après visite au commerçant du fort portugais qui nous invite pour samedi. (...)

V. me quite jusqu'à samedi $13 \mathrm{~h}-17 \mathrm{~h} 30$.

Dimanche 24 août - lettre $n^{\circ} 20$

J'ai oublié de noter ma conversation avec Verger qui est retourné au village où l'on a fait les 18 Iyaos.

O cruzamento de dados provenientes dos discursos oral e escrito que constroem escritura de campo de Bastide podem ser mais compreendidos com as 
palavras de McLuhan, que já notava a diferença "abissal" que distingue o "homem escrevente" do "homem tipográfico": as "culturas de manuscrito", ensinava ele, permanecem globalmente tátil-oral, e a escrita exerce então muito menos efeito do eu em nosso mundo. Idéia retomada por W.Ong, que situa o manuscrito na continuidade do oral, só intervindo a ruptura - progressivamente - com a imprensa. Entre a mensagem a transmitir e seu receptor, a produção do manuscrito introduz, tanto na transcrição do texto como na operação psicofisiológica do escrevedor, filtros que a imprensa em princípio eliminará, mas que, em contrapartida, são estreitamente análogos aos ruídos que parasitam a comunicação oral.

Em Lundi 25 août - Roger Bastide anota:

(...) Retour à 6 beures au campement. Faire reportage sur Ile Ife pour Cruzeiro.

Não conheço os originais dessa reportagem, nem tampouco o texto publicado pela revista O Cruzeiro. O texto ao qual tive acesso está em Verger/Bastide, Dimensões de uma amizade, com o título: "O mistério dos bronzes de Ifé e do Benin”, texto de Roger Bastide e fotos de Pierre Verger (Lühning, 2002: p.88).

No fragmento acima, temos uma produção que podemos chamar de autoetnográfica com diferentes vozes narrativas, entre observação e participação, auto-etnografia e interlocução de diversas linguagens: texto de Bastide e fotos de Verger. Dentre as fotos que interagem com o texto temos uma que é especialmente representativa de uma construção auto-etnográfica. A foto de $n^{\circ}$ 4: Roger Bastide ao lado do Oya Oraniyan, monumento muito antigo de pedra erguido na cidade de Ifé. Temos reunidos a presença do antropólogo, do fotógrafo antropólogo e o objeto de estudo. Construção de conhecimento a quatro mãos.

\section{Samedi 20 septembre}

Matin= fini rapport sur les marchés pour congrès des Africains de l'Ouest.

Verger le completera et le deposera lui-même à Ibadan.

Esse pequeno excerto é somente mais um exemplo da participação dos dois antropólogos. Temos então mais um texto a quatro mãos e "a concepção da escrita como representação de identidades" (Versiani, 2005: p.157) 
Bastide registra no diário de campo:

Mardi 22 - Fête de Pobe :notes spéciales en forme d'article

Puis, le soir, fête de Gelede (voir autre cahier)

O caderno onde ele anotou essas «notes spéciales en forme de article» está no título: [Le candomblé da Bahia et la Cérémonie de Ondo (Kobe)]. $\mathrm{Na}$ capa da frente do caderno temos com a letra de Bastide: Cérimonie de Ondo - Kobe, 22 de juillet - (fête des Ignames Neuves); e no verso do caderno, na quarta capa: Le Candomblé de Babia et la Cérémonie de Ondo.

A presença de Pierre Verger nesse texto se materializa enquanto escrita/ grafia. A construção gráfica do texto é compartilhada pelos dois antropólogos. O suporte da palavra é a escrita que certamente passou pela voz. A cada palavra corrigida fica patente para o leitor/pesquisador que as alterações foram efetivadas ao mesmo tempo em que acontecia um diálogo oral entre os antropólogos. Nesse momento eles são os "autores" que atuam sobre o protagonista que é o objeto de estudo, a performance ocorrida na festa dos inhames novos. Representada novamente pela pluralidade de linguagens, a escritura divide o espaço com o desenho de autoria de Bastide.

Mas essa presença aparentemente tão evidente, representada na escritura de campo por letras/grafias diferenciadas numa dinâmica de construção da escritura, onde uma substitui a outra por meio de correções, só pode ser identificada pelo leitor/pesquisador após um longo percurso pelos manuscritos. Onde sua presença estava mais corporificada é que mais se escondia. Como conduzir essa busca? $\mathrm{Na}$ escritura de campo de Bastide havia uma vOz "en cachette", uma voz materializada no suporte da escrita, mas de difícil identificação: uma escrita "en cachette". A escritura da festa dos inhames contava uma história de uma performance social. "Encarnadas em relatos escritos, tais histórias descrevem simultaneamente acontecimentos culturais reais e fazem afirmações adicionais, morais, ideológicas e mesmo cosmológicas. A escrita etnográfica é alegórica tanto no nível de seu conteúdo (o que ela diz sobre as culturas e suas histórias) quanto no de sua forma (as implicações de seu modo de textualização)". (J. Clifford, 2002: p.63). 


\section{Ouvir a voz "en cachette"}

Foi a escritura privada - epistolar - o elo organizador dessa viagem de estudo feita por Bastide à África. Os manuscritos me contaram essa história nos seus pequenos detalhes. Algum tempo depois, entre a chegada de um material e outro para consulta, eu lia muitas correspondências. Quando cheguei onde estavam classificadas as correspondências no inventário pude confirmar minha hipótese de que a letra diferente era a de Verger. A partir daquele dia não tive mais dúvidas.

$\mathrm{Na}$ rubrica Correpondance Générale, no título [VERGER, Pierre] ${ }^{13}$ havia quarenta e quatro cartas (11 datil., 33 manusc.) escritas entre 1947 e 1968. Além das cartas o inventário me informava que havia também "20 photos de Roger Bastide sur le terrain en Afrique”. Photos en Afrique 5II: 47 photos légendées et 28 ekta - chromes de la cérémonie « Briki». 13 photos légendées de la cérémonie «Sakete»; 22 photos [de la fête de Ogum] et 15 photos sans légende d'autres cérémonie [«Burrinha et Pobe»], 8 photos diverses d'Afrique. » Elas estavam também na escritura de campo chamadas pela numeração quando necessárias para interagirem na narrativa.

Das quarenta e quatro cartas, cinco são referentes à viagem realizada em 1958 à África d'Oeste. Tudo começou um ano antes da partida. Das cinco cartas somente uma é manuscrita; todas foram enviadas da África, exceto a primeira:

La Havanne 15 mai 57

"Je compte bien tester d'aller en Afrique en 58 -

Dites-moi où sont vos projets de voyage la-bas; il faut nous y trouver .

Croyez aussi bien

Votre Fatumbi Pierre Verger

Consulado de France»

Calzada 253 : Habana - Cuba"

\footnotetext{
${ }^{13}$ Espero conseguir em breve autorização para trabalhar com a correspondência de Pierre Verger / Roger Bastide e assim poder citar trechos importantes que confirmam e ilustram a argumentação do estudo.
} 
Aquele material esclarecia boa parte do mistério. Pierre Verger havia preparado a viagem de Bastide à África, em 1958.

Continuei minha busca e encontrei outro material que confirmou minha hipótese. Entre as peças contidas no título [Bibliographie (Voyage Afrique)], não havia somente bibliografia como o título indicava. Inesperadamente, encontrei sete cartas, e não oito como constavam na descrição do arquivo, datadas de 1953 a 1958. Das sete cartas, duas delas são referentes à viagem à África, em 1958. Ambas datilografadas, uma de 4 de abril de 1958, de Lagos, e a outra enviada de Ouidah, Wydah ou Ajuda (au choix) - assim escreveu Verger - em 18 de junho de 1958, vésperas da chegada de Bastide.

Uma das sete cartas que não estavam na categoria CORRESPONDÊNCIAS, mas na categoria NOTES, foi enviada para Bastide da Bahia em 30 de Junho, manuscrita, que por dedução acredito ter sido composta no ano de 1957, pois Verger a termina dizendo ao amigo:

"Je trouvé Bahia heureusement sans changements notables. Je dois en repartir dans 4 semaines pour le Dahomey où vous viendrez peut-être l'an prochain. »

Essa multiplicidade de "eus" que podemos notar nos cadernos de campo de Bastide é explicada talvez em parte pela presença de Pierre Verger na pesquisa de campo, pois ele também esteve lá. É também justificada pela amizade estendida por décadas até a morte de Roger Bastide em 1974 e pela presença constante do amigo, profissional e colaborador em outros artigos, livros e viagens, e principalmente pela parceria na escritura de campo da viagem feita à África, onde os dois antropólogos franceses da mesma geração traçaram o caminho de colaboração e troca constantes. Essa viagem de pesquisa sedimentou a amizade, mas, e principalmente, permitiu aos dois construírem uma história daqueles que: "On appelle Brésiliens au Dahomey et au Nigéria les descendants des anciens esclaves du Brésil qui, après la suppression du travail servile, sont retournés au pays de leurs Pères." (Roger Bastide)

"Se estamos condenados a contar histórias que não podemos controlar, que pelo menos não contemos histórias que acreditamos serem as verdadeiras." (J.Clifford, p.96 grifo do autor.).

Estas palavras ajudam o leitor/pesquisador a compreender a conduta de Bastide frente ao seu objeto de estudo e à sua escritura de campo, escritura 
em formação, ainda em estado bruto, ainda sem a "lapidação" das matérias editadas, contendo ainda os segredos, os mistérios da produção inédita e privada. Matéria inédita repleta de indagações, hipóteses, questões para serem resolvidas, comparações com outras realidades, outras experiências. São muitas as histórias contadas. Recontadas, elas são expostas e colocadas diante do "outro". São histórias que abrem espaço para o outro se dizer. Sem almejar o estatuto de verdadeiras, elas anseiam pela troca circular e dialógica de experiências e revelam as presenças que a escritura de campo cuidadosamente tantas vezes manteve "en cachette". 